responders and imprinted aggressors. Nat Rev Rheumatol. 2013 Jan;9(1):2433.

[2] Ren Z, Aerts JL, Vandenplas H, et al. Phosphorylated STAT5 regulates p53 expression via BRCA1/BARD1-NPM1 and MDM2. Cell Death Dis. 2016 Dec 22;7(12):e2560

[3] Lu M, Breyssens H, Salter V, et al. Restoring p53 Function in Human Melanoma Cells by Inhibiting MDM2 and Cyclin B1/CDK1-Phosphorylated Nuclear iASPP. Cancer Cell. 2016 Nov 14;30(5):822-823.

[4] Park JS, Lim MA, Cho ML, et al. p53 controls autoimmune arthritis via STAT-mediated regulation of the Th17 cell/Treg cell balance in mice. Arthritis Rheum. 2013 Apr;65(4):949-59.

Acknowledgements: This work is supported by grants from the National Natural Science Foundation of China (Grant number 81373182, 81373194, 8150060222 and U1401222). We would like to thank Jinjin Fan for her technical assistance.

Disclosure of Interest: None declared

DOI: 10.1136/annrheumdis-2017-eular.1554

\section{OP0156 METHOTREXATE INCREASES EXPRESSION OF THE CELL CYCLE REGULATORS LBH AND P21 AND REDUCES FIBROBLAST-LIKE SYNOVIOCYTE PROLIFERATION AFTER MITOGEN STIMULATION}

B. Bergström, H. Carlsten, A.-K.H. Ekwall. Rheumatology and Inflammation Research, Gothenburg University, Gothenburg, Sweden

Background: Activated fibroblast-like synoviocytes (FLS) are key effector cells in the joint in rheumatoid arthritis (RA). Local FLS proliferation is responsible for synovial hyperplasia, a key feature of the RA synovium correlating with disease activity. PDGF and IL-1b are known FLS mitogens. LBH is a transcription regulator and tumor suppressor, recently identified as a RA risk gene. We have demonstrated that $\mathrm{LBH}$ regulates FLS proliferation and that $\mathrm{LBH}$ expression is regulated by growth factors and by epigenetic mechanisms[1]. Methotrexate (MTX) is still the first-line treatment of RA but the target cells and mechanism of action of the low dose used in rheumatic diseases is largely unknown. Increased expression of cell cycle checkpoint genes[2] and modified DNA methylation[3] in immune cells have recently been described.

Objectives: The aim of this study was to investigate the effects of MTX on PDGF and IL1b-induced FLS proliferation in vitro and in particular on the expression of $\mathrm{LBH}$, cell cycle genes (CDKN1A/p21 and CCND1/cyclinD1) and on genes regulating DNA methylation (DNMTs) in order to further understand the pharmacodynamics of this drug in RA and to identify novel markers for drug response.

Methods: Primary FLS from RA patients and from patients with osteoarthritis (OA) were plated on day 0 in DMEM complete, pre-treated 24 hours with MTX or control medium day 1 , and stimulated with $20 \mathrm{ng} / \mathrm{ml} \mathrm{PDGF}+2 \mathrm{ng} / \mathrm{ml} \mathrm{IL}-1 \mathrm{~b}$ with or without 1 UM MTX in DMEM with 1\% FBS for 24-48 hours starting day 2. Cells were then harvested for qPCR for gene expression and flowcytometry for cell cycle analysis.

Results: Stimulating RA-FLS cultures $(n=3)$ with PDGF+IL-1b for 24 hours, pushed $24,5 \pm 3,5 \%$ cells into $\mathrm{G} 2 / \mathrm{M}$ phase compared to $3,4 \pm 0,8 \%$ in unstimulated controls. Interestingly, treating PDGF+IL1b stimulated FLS with MTX, significantly inhibited cell cycle progression $(4,6 \pm 1,9 \%$ in G2/M phase, $p=0,02)$. PDGF+IL-1b stimulation of FLS for 24 hours reduced LBH mRNA expression. However, in the presence of 1UM MTX the LBH mRNA expression was significantly higher in RA-FLS $(3,2 \pm 0,5$ fold, $p=0.002, n=5)$ and in OA-FLS $(2,2 \pm 0,5$ fold, $p=0,02, n=5)$ after PDGF+IL-1b stimulation compared to untreated controls. In addition, MTX treatment strikingly increased the CDKN1A expression $14,3 \pm 4,4$ fold $(p=0,006)$ of treated vs untreated stimulated FLS. Furthermore, we found that $1 \mathrm{uM} \mathrm{MTX}$ restored and increased a lowered DNMT1 mRNA expression to $144 \pm 12 \%$ after PDGF+IL1b stimulation. There were no significant effects of MTX on CCND1 or DNMT3a expression at investigated time points.

Conclusions: Therapeutic doses of MTX reduce mitogen induced FLS proliferation and significantly revert mitogen-induced reduction of $\mathrm{LBH}$ and p21 expression in RA FLS. MTX restores expression of DNMT1 suggesting that MTX might regulate gene expression and proliferation by affecting the epigenome.

\section{References:}

[1] Ekwall, A.K., et al., The Rheumatoid Arthritis Risk Gene LBH Regulates Growth in Fibroblast-like Synoviocytes. Arthritis Rheumatol, 2015. 67(5): p. 1193-202.

[2] Spurlock, C.F., 3rd, et al., Methotrexate increases expression of cell cycle checkpoint genes via JNK activation. Arthritis Rheum, 2012. 64(6): p. 1780-9.

[3] Cribbs, A.P., et al., Methotrexate Restores Regulatory T Cell Function Through Demethylation of the FoxP3 Upstream Enhancer in Patients With Rheumatoid Arthritis. Arthritis Rheumatol, 2015. 67(5): p. 1182-92.

Disclosure of Interest: None declared

DOI: 10.1136/annrheumdis-2017-eular.5079

\section{OP0157 APOPTOSIS RESISTANCE OF SYNOVIAL FIBROBLASTS OF PATIENTS WITH RHEUMATOID ARTHRITIS IS REGULATED BY THE LONG NON-CODING RNA FAS-AS1}

A. Pajak $^{1}$, Y. Horai $^{2}$, E. Pachera ${ }^{1}$, M. Brock ${ }^{2}$, S. Gay ${ }^{1}$, M. Neidhart ${ }^{1}$,

O. Distler ${ }^{1}$, A. Jungel ${ }^{1}$ on behalf of yes. ${ }^{1}$ Department of Rheumatology;

${ }^{2}$ Division of Pulmonology, University Hospital Zurich, Zurich, Switzerland

Background: Apoptosis resistance is thought to contribute to the accumulation of synoviocytes in the affected joints of patients with rheumatoid arthritis (RA). Of particular interest, the Fas receptor (FasR) - Fas ligand (FasL) apoptotic pathway appears altered in RA ${ }^{1}$. Long non-coding RNAs (IncRNAs) are emerging as key regulators of gene expression. Their role in disease, however, is still poorly understood. The recently described IncRNA FAS-AS1 has been implicated in alternative splicing of FasR. This results in increased amounts of soluble FasR (sFasR) and thereby prevents FasL-induced cell death ${ }^{2,3}$. Whether IncRNA FAS-AS1 is involved in the apoptosis resistance of synovial fibroblasts in RA is unknown.

Objectives: To assess the regulatory role of IncRNA FAS-AS1 in the apoptosis resistance of synovial fibroblasts from patients with RA (RASF).

Methods: Levels of expression of IncRNA FAS-AS1 were measured in RASF and synovial fibroblasts from patients with osteoarthritis (OASF) by qPCR using SYBRGreen detection. Cells were treated with $\mathrm{TNF} \alpha(10 \mathrm{ng} / \mathrm{ml}, 24 \mathrm{~h})$ and/or with FasL $(50 \mathrm{ng} / \mathrm{ml}, 18 \mathrm{~h})$ to assess the secreted amount of sFasR by ELISA and the induction of apoptosis by Annexin $V$ staining followed by flow cytometry. LncRNA FAS-AS1 was silenced using locked nucleic acid antisense oligonucleotides (GapmeR).

Results: There was no significant difference in basal levels of IncRNA FAS-AS1 expression between RASF and OASF ( $n=4$ each). TNF $\alpha$ stimulation of synovial fibroblasts, regardless of the disease context (RA or OA), resulted in higher than 6-fold induction of IncRNA FAS-AS1 expression (6.45 $\pm 1.39 ; p<0,05 ; n=4$ for RASF and $6.26 \pm 1.47 ; p=0.05 ; n=4$ for OASF). In addition, TNF $\alpha$ stimulation induced secretion of $S F a s R$ in RASF from $107 \pm 74$ to $390 \pm 274 \mathrm{pg} / \mathrm{ml} \quad(p<0.05$; $\mathrm{n}=6)$ and OASF from $69 \pm 54$ to $249 \pm 134 \mathrm{pg} / \mathrm{ml}(\mathrm{p}<0.05 ; \mathrm{n}=6)$. FasL induced apoptosis in both RASF and OASF (55-75 $\pm 13 \%)$. However, pretreatment with TNF $\alpha$ reduced the FasL-induced apoptosis in RASF by $25 \pm 19 \%$ and in OASF by $15 \pm 10 \%$. Silencing with GapmeR successfully decreased the expression of IncRNA FAS-AS1 by $40 \pm 22 \%$ SEM. Most interestingly, silencing of IncRNA FASAS1 reverted the TNF $\alpha$ inhibitory effect on FasL-induced apoptosis by $37 \pm 11 \%$ $(\mathrm{n}=4)$.

Conclusions: Our data revealed a novel mechanism, which may underlie apoptosis resistance in RASF. We showed that in a pro-inflammatory cytokine milieu, IncRNA FAS-AS1 up-regulates the release of sFasR and thereby may lower the responsiveness of cells to death signals. Thus, targeting IncRNA FAS-AS1 might prevent apoptosis resistance and synovial hyperplasia in RA.

References:

[1] Hong et al., Life Sciences. 2015; Feb 1; 122:37-41.

[2] Seghal et al., Leukemia. 2014; Dec 28(12); 2376-87.

[3] Villamizar et al., Oncotarget. 2016; Mar 22; 7(12):13810-26.

Disclosure of Interest: A. Pajak: None declared, Y. Horai: None declared, E. Pachera: None declared, M. Brock: None declared, S. Gay Grant/research support from: EU project BTCure, IAR, Consultant for: GSK, M. Neidhart Grant/research support from: Baugartenstiftung, O. Distler Grant/research support from: Actelion, Bayer, Boehringer Ingelheim, Pfizer, Sanofi, Consultant for: 4 D Science, Actelion, Active Biotec, Bayer, Biogenldec, BMS, Boehringer Ingelheim, ChemomAb, EpiPharm, espeRare foundation, Genentech/Roche, GSK, Inventiva, Lilly, medac, Mepha, Medlmmune, Mitsubishi Tanabe Pharma, Pharmacyclics, Pfizer, Sanofi, Serodapharm, Sinoxa, Speakers bureau: AbbVie, iQone Healthcare, Mepha, A. Jungel: None declared

DOI: 10.1136/annrheumdis-2017-eular.2677

\section{OP0158 PREVALENCE OF IMMUNIZATION OF PATIENTS WITH AUTOIMMUNE DISEASE IN MEXICO}

A. Arellano-Martinez, V. Gonzalez-Diaz, G.E. Martinez-Bonilla, S. Cerpa-Cruz, S.R. Gutierrez-Ureña, J. Reyes-Rueda, K.M. Garcia-Osuna, E. Gonzalez-Diaz. Rheumatology Service, Hospital Civil Fray Antonio Alcalde, Guadalajara, Mexico

Background: Current guidelines recommend immunization in patients with autoimmune diseases and use of immunosuppressants including biological treatment. Despite the above, the frequency of immunization is unknown in our population.

Objectives: To identify the prevalence of immunization in patients with autoimmune disease in a Rheumatology Service of a third level hospital in Mexico.

Methods: Observational, descriptive, cross-sectional study. Consecutive outpatients with autoimmune diseases who attended the Rheumatology Service of the Hospital Civil of Guadalajara during a period of 2 months (Dec. and Jan.) were included. A questionnaire was carried out to obtain demographic and immunization data. Descriptive statistical analysis was performed.

Results: 1208 patients were surveyed, $484(40 \%)$ had a diagnosis of autoimmune disease; of whom 286 (59\%) were on immunosuppressant therapy. 321 patients had a complete immunization during childhood. None of the patients knew what vaccines should by received with their diagnosis. When asked if they had been invited for immunization and from whom, 24 reported that their 
general practitioner, 126 immunization campaign, 19 nurse, 9 rheumatologist, 4 pulmonologist, 1 infectious disease specialist, 1 family doctor and 1 internist. 260 $(54 \%)$ reported having their immunization records. Only 37 had been vaccinated with influenza, 27 pneumococcus, 4 human papilloma virus and 2 Hepatitis B in the past. $372(77 \%)$ accepted the invitation to be vaccinated on the day of their interview, but only $72(19 \%)$ went to get the immunization; 41 of whom were given anti-influenza vaccines and 34 Pneumococcus (PPSV 23). The main causes for which the patient considers not to be vaccinated are: $85 \%$ "Because $m y$ treating doctor has not recommended me to go get vaccinated", 36\% "They often do not have the vaccine to apply", $36 \%$ "I forget to get the vaccine on time", $31 \%$ "I think the application of the vaccine can make me sick", $14 \%$ "A vaccination center is not accessible", $7 \%$ "I think it is not useful to get vaccinated", and $5 \%$ "My doctor recommended me not to get vaccinated". These patients presented a total of 172 recurrent infections that included: upper airway infection 55, pneumonia 4 and others; 90 hospitalizations were required due to infection of which the main were due to: pneumonia 29, pulmonary tuberculosis 4 , kidney 3 , bone 1 and meningitis 1 .

Conclusions: Immunization in this group of patients is low and rarely accepted mainly because their rheumatologist does not provide them with this information and due in general to a lack of information. This action is extremely important as it might reduce some serious infectious processes that lead to hospitalizations and increase the mortality in these immunosuppressed patients.

\section{References:}

[1] Singh Jec. 2015 American College of Rheumatology Guideline for the Treatment of Rheumatoid Arthritis. Arthritis and Rheumatology. 2015;: p. $1-26$.

[2] Zimmerman Rec. Barriers and facilitators of pneumococcal vaccination among the elderly. Vaccine. 2003;: p. 1510-1517.

[3] Cardiel Mec. Actualización de la Guía Mexicana para el Tratamiento Farmacológico de la Artritis Reumatoide del Colegio Mexicano de Reumatología. Reumatología Clínica. 2013;: p. 1-14.

Disclosure of Interest: None declared

DOI: 10.1136/annrheumdis-2017-eular.6721

\section{OP0159 THE INITIATION, BUT NOT THE PERSISTENCE, OF EXPERIMENTAL SPONDYLOARTHRITIS IN HLA-B27/HU $\beta 2 M$ TRANSGENIC RATS IS CRUCIALLY DEPENDENT ON THE IL-23 AXIS}

M. Van Tok ${ }^{1}$, S. $\mathrm{Na}^{2}$, J. Taurog ${ }^{3}$, D. Baeten ${ }^{1}$, L. van Duivenvoorde ${ }^{1} .{ }^{1}$ Clinical Immunology and Rheumatology/Experimental immunology, Academic Medical Center, Amsterdam, Netherlands: ${ }^{2}$ Eli Lilly and Co, San diego, CA: ${ }^{3}$ Rheumatic Diseases Division, Department of Internal Medicine, UT Southwestern Medical Center, Dallas, TX, United States

Background: The pro-inflammatory cytokine $\mathrm{IL}-17 \mathrm{~A}$ is a central driver of pathology in human spondyloarthritis (SpA). IL-17A production was originally proposed to be dependent on the upstream cytokine, IL-23. Emerging preclinical and clinical evidence from SpA-related diseases suggest, however, that IL-17A and IL-23 have a partially overlapping but distinct biology.

Objectives: Here, we aimed to assess to what extend pathogenic IL-17A is dependent on IL-23 in SpA by selectively targeting the IL-23R in the HLA$\mathrm{B} 27 / \mathrm{Hu} \beta 2 \mathrm{~m}$ transgenic rat model of SpA, which we showed previously to be IL-17A-dependent.

Methods: HLA-B27/Huß2m tg rats were immunized with low dose heat-inactivated M. tuberculosis/IFA. Rats were treated with a depleting anti-mouse/rat chimeric IL-23R antibody or PBS in a prophylactic (treatment initiation after immunization, before disease onset) or therapeutic (treatment initiation after disease onset) experiment. Clinical measurements included spondylitis and arthritis scores and hind paw swelling (plethysmometry). At the end of the study spleen and lymph nodes were used to assess cytokine expression, serum samples were analyzed for exposure to anti-IL23R.

Results: In the prophylactic treatment strategy, $58 \%$ and $67 \%$ of the rats in the control group developed spondylitis and arthritis, respectively. The average arthritis score at the end of the study was $3.9 \pm 1.1$ and the average hind paw swelling was $0.35 \pm 0.09 \mathrm{~cm}^{3}$. Prophylactic treatment with anti-IL-23R completely protected the rats against the development of spondylitis as well as arthritis. In the therapeutic treatment strategy, however, anti-IL23R treatment failed to reduce the incidence or decrease the severity of experimental SpA (fig. 1). With an average increase in arthritis score after the start of treatment of $1.6 \pm 2.8$ versus $2.1 \pm 2.5$ and an increase in paw swelling of $0.6 \pm 0.7$ versus $0.3 \pm 0.6 \mathrm{~cm}^{3}$ in anti-IL23R treated versus control animals. The differential effect of IL-23R targeting in the initiation phase versus established disease could not be explained by pharmacokinetic differences as serum analyses revealed similar exposure levels. Mechanistically, the expression of presumably downstream effector cytokines such as IL-17A $(p<0.05)$ and IL-22 $(p<0.01)$ was reduced in the popliteal lymph nodes of rats treated prophylactically with anti-IL23R versus controls, with a similar trend in spleen. Accordingly, IL-17A production upon ex vivo re-stimulation was reduced in samples from prophylactically treated rats. In contrast, similar popliteal lymph node expression data in samples from the therapeutic experiment indicate a twofold increase in IL-17A expression and no difference in IL-22 expression in the anti-IL23R treated rats compared to controls.

Conclusions: IL-17A expression and production is dependent on the IL-23

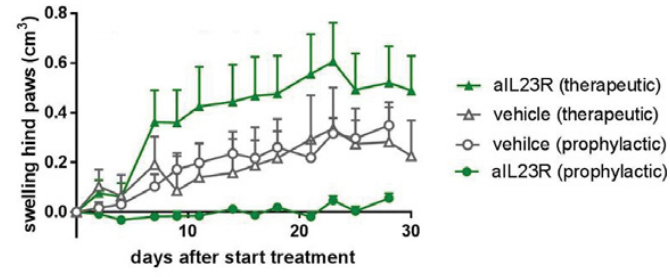

Figure 1: Swelling of the hind paws during follow up in prophylactic versus therapeutic treatment with anti-ll-23R or vehicle control (data are means + - SEM)

axis in the initiation phase of experimental SpA but not in established disease. Accordingly, targeting of this axis with an anti-IL23R antibody completely prevented the onset of arthritis and spondylitis in $\mathrm{HLA}-\mathrm{B} 27 / \mathrm{Hu} 32 \mathrm{~m}$ transgenic rats, but failed to reduce axial and peripheral joint inflammation in established disease. The cellular origin of IL-23-independent IL-17A production in established disease and the relevance to human SpA remains to be further investigated.

Disclosure of Interest: M. Van Tok: None declared, S. Na Employee of: Eli Lilly and Co, J. Taurog Grant/research support from: AbbVie, Anges, Inc, and Celgene, D. Baeten Grant/research support from: AbbVie, Pfizer, UCB, MSD, Roche, BMS, Novartis, Eli Lilly, Janssen, Glenmark, Boehringer-Ingelheim, Employee of: part-time employee of UCB, L. van Duivenvoorde Grant/research support from: Abbvie, Boehringer-Ingelheim

DOI: 10.1136/annrheumdis-2017-eular.5248

\section{OP0160 GUT-DERIVED TNF AS RISK FACTOR FOR THE DEVELOPMENT OF SACROILIAC INFLAMMATION}

K. Debusschere ${ }^{1}$, H. Cypers ${ }^{2}$, P. Jacques ${ }^{2}$, F. Van den Bosch ${ }^{2}$, D. Souza ${ }^{3}$, M. Brown ${ }^{3}$, G. Nabozny ${ }^{3}$, D. Dove ${ }^{3}$, A. Klimowicz ${ }^{3}$, D. Elewaut ${ }^{1} .{ }^{1}$ Ghent University - VIB; ${ }^{2}$ Ghent University Hospital, Gent, Belgium; ${ }^{3}$ Boehringer Ingelheim, Ridgefield, United States

Background: An intruiging link exists between gut and joint inflammation in spondyloarthritis (SpA). About $50 \%$ of patients has subclinical (eg. microscopic) gut inflammation, which represents a risk factor for development of Crohn's disease, sacroiliac inflammation and evolution in to Ankylosing Spondylitis. However, the underlying mechanisms are still relatively poorly understood.

Objectives: Our goal was to examine the relationship between TNF, microscopic gut inflammation and axial inflammation using human samples and a novel mouse model. We speculated that TNF in the gut represents an important risk factor for disease severity and progression in SpA.

Methods: We examined in situ expression of TNF, TNFR1 and TNFR2 using triple in situ hybridisation in gut biopsies of human SpA patients. Furthermore we generated intestinal specific human TNF transgenic mice, in which hTNF is under control of a rat iFABP (fatty acid binding protein) promoter, generating a mouse-model over-expressing human TNF in the ileum. These mice, together with wild type littermates, were evaluated for the development of arthritis up until the age of 13 weeks after which they were euthanized and ankle and sacroiliac joints as well as ileum were processed for histology.

Results: There was a marked upregulation of TNF in inflamed versus noninflamed gut biopsies of human SpA patients. We also noted a predominant upregulation of TNFR1 on intestinal epithelium and TNFR2 in lamina propria respectively. Of interest, IL-17 and IL-23 were also markedly increased while IL-22 was most abundant in chronically inflamed samples. In line with this, we found that patients with gut inflammation had a higher need for anti-TNF therapy and their degree of clinical response after anti-TNF was also markedly higher. Our transgenic mice exhibited a runt phenotype and hallmarks of inflammatory bowel disease, including increased intestinal permeability and inflammation compared to their wild-type littermates. While in peripheral joints no clear signs of arthritis were observed, the sacroiliac joints in transgenic mice, by contrast, showed marked signs of inflammation as well as bone erosion and destruction. Conclusions: These data propose a new paradigm that gut-derived TNF is sufficient to trigger sacroiliitis and provide an alternate explanation on the relationship between gut inflammation, evolution to inflammatory bowel disease and axial inflammation in SpA.

Disclosure of Interest: None declared

DOI: 10.1136/annrheumdis-2017-eular.4999

\section{OP0161 THE JAK1 SELECTIVE INHIBITOR FILGOTINIB REGULATES BOTH ENTHESIS AND COLON INFLAMMATION IN A MOUSE MODEL OF PSORIATIC ARTHRITIS}

C. Robin-Jagerschmidt, S. Lavazais, F. Marsais, A. Monjardet, A. Cauvin, C. Saccomani, I. Parent, D. Merciris, E. Chanudet, M. Borgonovi, L. Lepescheux, M. Auberval, S. Dupont, P. Clement-Lacroix, R. Galien. Galapagos SASU, Romainville, France

Background: Psoriatic arthritis (PsA) is a heterogeneous chronic inflammatory disease characterized by the association of musculoskeletal involvement and extra-skeletal symptoms such as psoriasis and Inflammatory Bowel Disease 